This is the final peer-reviewed accepted manuscript of

FANTI, FEDERICO; Miyashita, Tetsuto; CANTELLI, LUIGI; Mnasri, Fawsi; Dridi, Jihed; CONTESSI, MICHELA;

CAU, ANDREA: The largest thalattosuchian (Crocodylomorpha) supports teleosaurid survival across the Jurassic-Cretaceous boundary. CRETACEOUS RESEARCH, 61. ISSN: 0195-6671

DOI: 10.1016/j.cretres.2015.11.011

The final published version is available online at:

http://dx.doi.org/10.1016/j.cretres.2015.11.011

Rights / License:

The terms and conditions for the reuse of this version of the manuscript are specified in the publishing policy. For all terms of use and more information see the publisher's website.

This item was downloaded from IRIS Università di Bologna (https://cris.unibo.it/)

When citing, please refer to the published version. 


\title{
The largest thalattosuchian (Crocodylomorpha) supports teleosaurid survival across the Jurassic-Cretaceous boundary
}

\author{
Federico Fanti a, b, Tetsuto Miyashita ${ }^{\text {c }}$, Luigi Cantelli a , Fawsi Mnasri ${ }^{\text {d }}$, Jihed Dridi ${ }^{\text {d }}$, \\ Michela Contessi e, Andrea Cau a, b, * \\ a Dipartimento di Scienze Biologiche, Geologiche e Ambientali, Alma Mater Studiorum, Università di Bologna, Via Zamboni 67, 40126 Bologna, Italy ${ }^{\text {b }}$ \\ Museo Geologico Giovanni Capellini, Alma Mater Studiorum, Università di Bologna, Via Zamboni 63, 40126 Bologna, Italy \\ ${ }^{c}$ Department of Biological Sciences, University of Alberta, Edmonton, T6G 2E9 Alberta, Canada \\ d Office National Des Mines, Service Patrimoine Géologique, 24 Rue de l'Energie 8601, La Charguia, 2035 Tunis, Tunisia \\ e Museo Civico di Scienze Naturali Malmerendi, Via Medaglie d'Oro 51, 48018 Faenza, Italy
}

\section{A R T I C L E I N F O}

Keywords:

Lower Cretaceous

Machimosaurus

Teleosauridae

Thalattosuchia

Tunisia

\begin{abstract}
A B S T R A C T
A new teleosaurid from the Lower Cretaceous of Tataouine (Tunisia), Machimosaurus rex sp. nov., definitively falsifies that these crocodylomorphs faced extinction at the end of the Jurassic. Phylogenetic analysis supports its placement closer to $M$. hugii and M. mosae than M. buffetauti. With the skull length up to $160 \mathrm{~cm}$ and an estimated body length of $10 \mathrm{~m}, M$. rex results the largest known thalattosuchian, and the largest known crocodylomorph at its time. This giant thallatosuchian probably was an ambush predator in the lagoonal environments that characterized the Tethyan margin of Africa during the earliest Cretaceous. Whether the Jurassic Cretaceous mass extinction was real or artefact is debated. The dis covery of $M$. rex supports that the end Jurassic crisis affected primarily Laurasian biota and its purported magnitude is most likely biased by the incomplete Gondwanan fossil record. The faunal turnovers during the $\mathrm{J} \mathrm{K}$ transition are likely interpreted as local extinction events, triggered by regional ecological factors, and survival of widely distributed and eurytypic forms by means of habitat tracking.
\end{abstract}

\section{Introduction}

The Jurassic Cretaceous ( $\mathrm{J}$ ) transition has been considered a complex phase of global extinctions in both terrestrial and marine faunas, which affected rates of lineage diversification and morphological evolution during the Early Cretaceous (Bakker, 1978, 1998; Sepkoski, 1984; Bardet, 1994; Benton, 2001; Upchurch and Barrett, 2005; Lu et al., 2006; Benson et al., 2010). Whether this event was real (i.e., a complex combination of clade specific extinction patterns driven by physical and biotic factors) or repre sents an artefact remains unresolved (Gasparini et al., 2004; Bambach, 2006; Benson et al., 2010; Ruban, 2012; Newham et al., 2014). Among speciose clades of Jurassic marine reptiles, tele osauroid crocodylomorphs stand as the sole that supposedly went extinct at the Jurassic Cretaceous boundary (Young et al., 2014a), with all purported Cretaceous remains re interpreted as belonging

\footnotetext{
* Corresponding author. Dipartimento di Scienze Biologiche, Geologiche e Ambientali, Alma Mater Studiorum, Università di Bologna, Via Zamboni 67, 40126 Bologna, Italy.

E-mail address: cauand@gmail.com (A. Cau).
}

to other reptilian clades, in particular, to the other thalattosuchian clade, Metriorhynchoidea (Young et al., 2014a,b). From a palaeogeographic perspective, Teleosauroidea is known largely from Europe (Vignaud, 1995), with Gondwanan remains rare, often limited to problematic or extremely fragmentary specimens (e.g., Martin et al., 2015; Young et al., 2014a).

In December 2014, the articulated remains of a giant crocodylomorph were found during prospecting activities at the Touil el Mhahir locality, Tataouine Governorate, Tunisia (Figs. 1, 2). In this study, we describe this new specimen and determine its affinities and stratigraphic placement. The results of our analyses support the erection of a new species of thalattosuchian teleosaurid, Machimosaurus rex. Furthermore, we discuss the implications of this new African taxon in the debate on the end Jurassic biotic crisis.

\section{Material and methods}

Specimens collected at the Touil el Mhahir locality in 2014 are housed in the Musée de l'Office National Des Mines (Ministère de l'Industrie et de la Technologie, Tunis), under the accession 
numbers ONM NG 1-25, 80, 81, and 83-87. Microvertebrate fossils, field notes and locality coordinates, and the 3D data are housed at the Museo Geologico Giovanni Capellini (MGGC, Bologna, Italy). Assemblage data were interpreted from the final quarry map as well as from field notes: all elements were mapped using a $1 \mathrm{~m}^{2}$ grid box. Following the discovery of small elements from the surface of the outcrop, a total of $2.5 \mathrm{~kg}$ of sandy and clayish sediments were collected from both the excavation site and the matrix surrounding the skull for screen washing. Samples were soaked with water and $\mathrm{H}_{2} \mathrm{O}_{2}(5 \%)$ and screened using progressive sieves of 1 $\mathrm{mm}, 200 \mu \mathrm{m}$, and $63 \mu \mathrm{m}$. With $100 \%$ of collected matrix screened and sorted, a total of 231 specimens were identified. The collected specimens were primarily identified and compared with those described and illustrated by Cuny et al. (2004), Cuny et al. (2010) (Early Cretaceous of southern Tunisia), and Pouech et al. (2015) (Berriasian of France). Furthermore, during the preparation of the skull, four displaced osteoderms lying slightly imbricated on the snout were recovered and prepared (ONM NG 14 17).

\subsection{Taxonomy}

The taxonomic content of the genus level ranked clade Machi mosaurus von Meyer, 1837, is controversial. Young et al. (2014a,b) recognised four species of Machimosaurus: M. buffetauti Young et al., 2014b, M. hugii von Meyer, 1837, M. mosae Sauvage and Liénard, 1879, (all from Europe) and M. nowackianus (von Huene, 1938) (from Ethiopia). Martin et al. (2015) challenged the distinction among the first three species suggested by Young et al.(2014a,b), referring all European Machimosaurus to M. hugii, and considered M. nowackianus as a nomen dubium. We follow the distinction among the species of Machimosaurus as suggested by Young et al. (2014b) since both morphological and stratigraphic disparities among the three European morphotypes support a species level distinction among them, and tested whether the in clusion of the new Tunisian material in a phylogenetic analysis of Teleosauroidea further supports or challenges a taxonomic distinction among the European Machimosaurus.

\subsection{Phylogenetic analysis of Thalattosuchia}

In order to analyse the evolutionary affinities of the Tunisian thalattosuchian, we performed Bayesian inference methods integrating the morphological and stratigraphic data with BEAST (Rambaut and Drummond, 2009; Drummond et al., 2012) following the method of Lee et al. (2014). The morphological dataset is based on Young (2014) and modified by Cau (2014) after the a priori exclusion of all non thalattosuchian taxa. As branch duration esti mation and cladogenesis timing using Bayesian inference requires sampling among both constant characters and autapomorphies of terminal taxa - not solely among synapomorphies of internodes (Lee et al., 2014) - we retained all characters of the dataset of Young (2014), including those resulted phylogenetically uninformative by the a priori removal of most crocodyliform taxa from the ingroup. The ingroup was consequently expanded by the inclusion of Machimosaurus buffetauti (based on Martin and Vincent, 2013, and Young et al., 2014b) and the new Tunisian thalattosuchian. One Triassic pseudosuchian closely related to Crocodylomorpha (Post osuchus Chatterjee, 1985) and one basal crocodyliform (Protosuchus Brown, 1934) were used as outgroups - with the former set as root of the trees - according to the recent revision of thalattosuchian affinities by Wilberg (2015) indicating a non crocodyliform place ment for Thalattosuchia. Stratigraphic data and age constraints for each terminal were obtained primarily from the Paleobiology Database (http://paleobiodb.org/) and from the literature, using
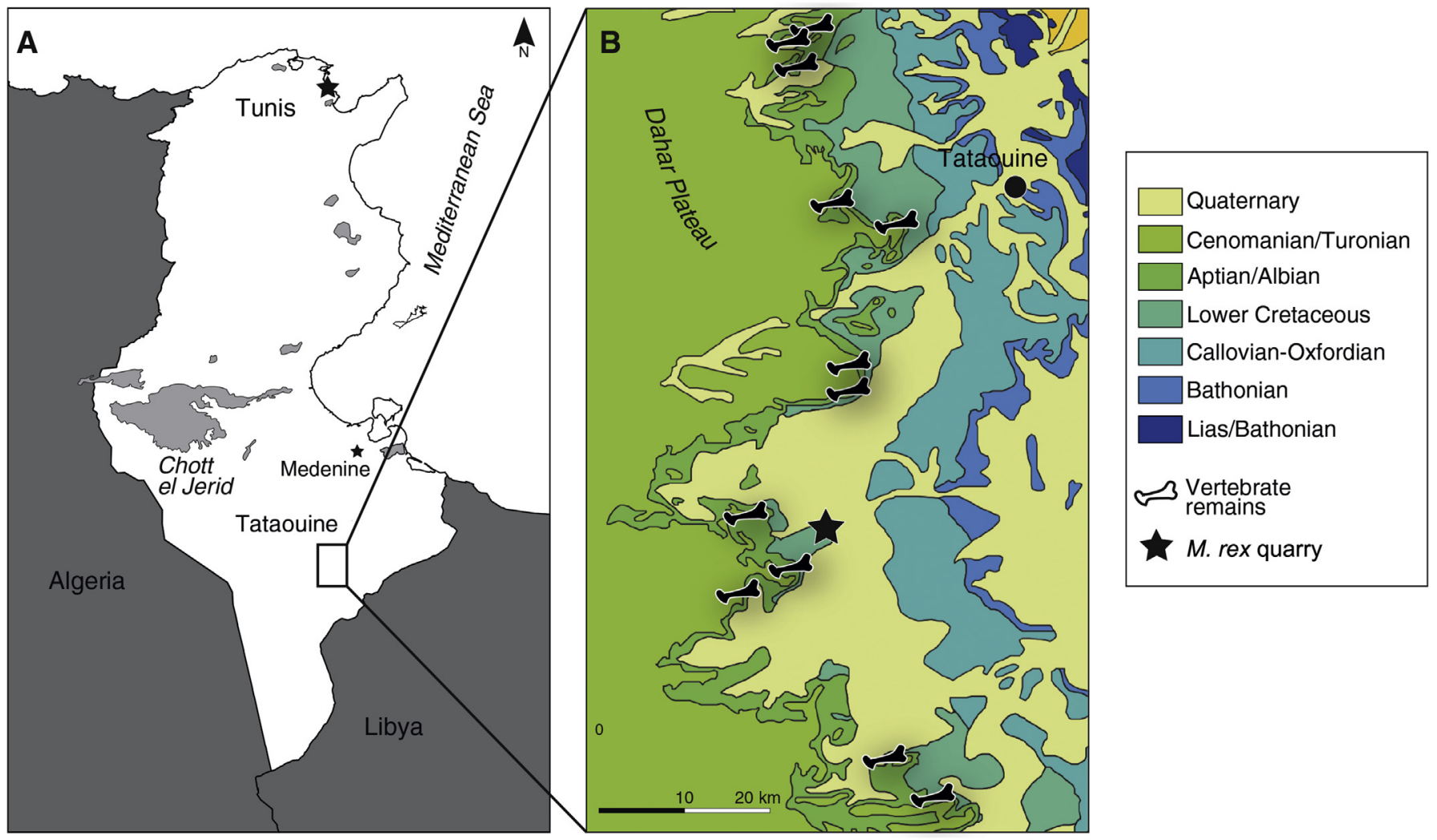

Fig. 1. (A) Geographic location and type locality of M. rex. (B) Simplified geological map of the Tataouine basin of southern Tunisia showing the Touil el Mhahir locality. 

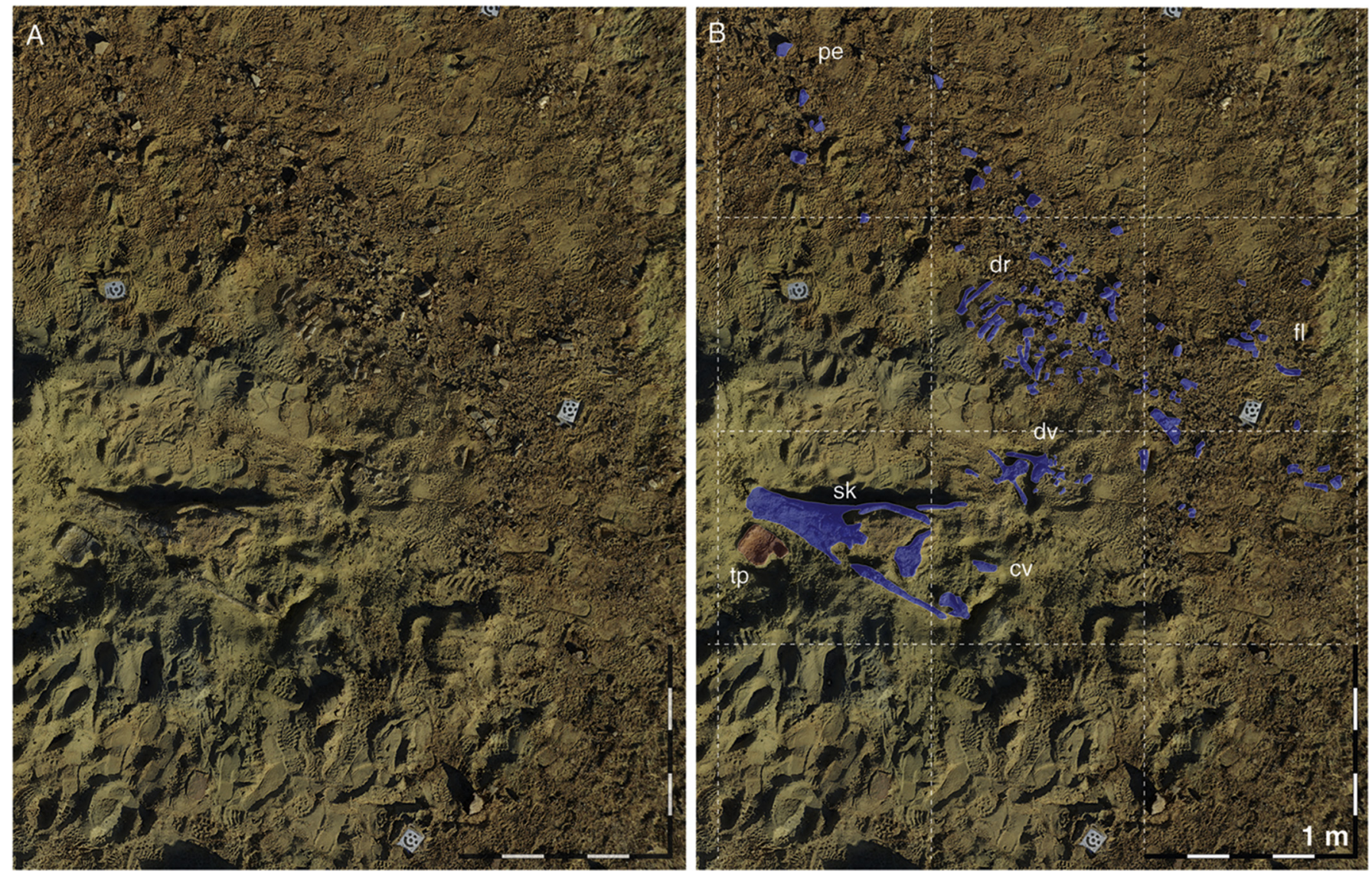

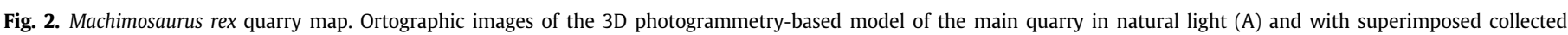
elements (B). Abbreviations: cv, cervical vertebrae; dr, dorsal ribs; dv, dorsal vertebrae; fl, forelimb bones; pe, pelvic elements; sk, skull; tp, turtle hyoplastron.

provided geochronological ages for the formations in which the taxa were found or the mean of the geologic stages associated with those formations. The root age prior (i.e., the maximum age of the last common ancestor of all included taxa) was set along a uniform range between 218 Mya (the age of the oldest terminal included, Postosuchus) and 252 Mya (the Permian Triassic boundary). The latter was considered as a 'loose' hard constraint that consistently pre dates the age of the oldest potential crocodylomorphs and basal loricatans. In the analysis, rate variation across traits was modelled using the gamma parameter, and rate variation across branches was modelled using an uncorrelated relaxed clock. The analyses used four replicate runs of 40 million generations, with sampling every 4000 generations. Burnin was set at $20 \%$, and the Maximum Clade Credibility Tree (MCCT) of the merged four postburnin samples was used as framework for phyletic reconstruction.

\section{3. $3 D$ photogrammetry and modelling}

During the last decade, the development of Structure from Motion (SFM) techniques has been dramatically improved allowing accurate reconstruction of 3D structures processing 2D images (Koenderink and Doorn, 1991; Beardsley et al., 1996; Trucco and Verri, 1998; Dellaert et al., 2000; Haming and Peters, 2010; Fanti et al., 2013; Engel et al., 2014; Fanti et al., 2015). We acquired digital models of the Machimosaurus quarry, the skull (both dorsal and ventral views), and the prepared dorsal vertebrae, using high resolution photogrammetry. We used Agisoft PhotoScan Profes sional, and Meshlab for this technique. The models were built as in the following procedure: 1 . positioning of coded targets so that $70 \%$ of photos frame at least one target (actual distances between targets will serve to include accurate measurement tools in the model); 2. proper preparation of the light so that variations in the enlightenment are minimal; 3. prearrangement of a photoshooting path. In order to properly perform the metric reconstruction in the 3D model, it was mandatory to work with a camera with a fixed focal length lens. The lens profile for Agisoft Photoscan was set using the software Agisoft lens. Automatic check of images verified the complete coverage of selected objects before proceeding with the alignment of frames that originated the first point cloud based on corresponding points recognized in different photos. Once the consistency of the generated surface were verified, a photographic texture was generated.

\section{Stratigraphy and age}

The Touil el Mhahir locality (the exact locality data can be obtained upon request) is located less than $50 \mathrm{~km}$ to the south west of the city of Tataouine and about $25 \mathrm{~km}$ to the north west of Remada (Fig. 1). Substantial erosion resulted in a badland like morphology that exposed the basal beds of the Douiret Formation, and in particular of the Douiret Sand Member. In the Tataouine Basin, the Douiret Formation uncoformably overlays the Boulouha Formation which has been assessed a Barremian age based on the occurrence of the Cretaceous brachiopod Loriolithyris russillensis (De Loriol, 1866), in the upper beds of the unit (Peybernes et al., 1996; Ouaja et al., 2004; Bodin et al., 2010). However, recent re evaluation of stratigraphic and biostratigraphic data in southern Tunisia and western Lybia (Cuny et al., 2010; Le Loeuff et al., 2010; Fanti et al., 2012) placed the lower, sandy deposits of the Douiret Formation in the Barremian. Specifically, the age of the Douiret Formation has 
been assessed primarily through a detailed, basin scale revision of the stratigraphic occurrence and lateral variability of fossil bearing strata (Fanti et al., 2012). The occurrence of the hibodontid Eger tenodus Maisey, 1987, and Gyrodus Agassiz, 1833, in the Douiret Formation supports an Hauterivian Barremian age for this unit. In fact, Rees and Underwood (2008) indicate the latest ascertain record of Egertenodus in the Barremian of Spain, and Kriwet and Schmitz (2005) note the youngest record of Gyrodus in the Hau terivian of Germany. Therefore, although a pre Hauterivian age of the lower Douiret beds cannot be excluded, based on 1) the Early Cretaceous age of the Boulouha Formation, and 2) stratigraphic and biostratigraphic data provided by Cuny et al. (2010), Le Loeuff et al. (2012), and Fanti et al. (2012), we conservatively consider the age of the Touil el Mhahir locality as Hauterivian Barremian.

The deposits are characterized by repeating, fining up se quences of fine grained sand and clay, capped by an alternating sequence of clay and dolostone or dolomitized sandstone. The M. rex quarry is located approximately $20 \mathrm{~m}$ above the fossil rich conglomerate that, on a basin scale, marks the base of the Douiret Formation (Fanti et al., 2012). Furthermore, we report iso lated teeth of Machimosaurus sp. occurring in several localities from the Douiret Formation deposits along the Dahar Escarpment (i.e. El Hmaima, Jebel Haddada, Boulouha localities; Fanti et al., 2012) of southern Tunisia, supporting that this genus is a representative of this formation.

\section{Taphonomy and paleoecology}

The type specimen of Machimosaurus rex represents the first articulated vertebrate from the Douiret Formation and the second Mesozoic archosaur skeleton collected in Tunisia (Fanti et al., 2012, 2013, 2015). The skeleton lies on its ventral side with the head rotated clockwise toward the right side of the body (Figs. 2-4). Only three teeth were found preserved in the alveoli (Fig. 5), whereas seven were shed along the snout. Although preserved elements show no evidence of major pre burial transportation (Figs. $2-8 \mathrm{~A}$ ), the overall posture (i.e. the body lying on its ventral side and the head curved on the right side of the body) combined with displacement of osteoderms and the missing anterior end of the snout strongly suggest that there was some influence from paleocurrents (paleoflow from the south east). In addition, the right side of the skull is laterally compressed (see also the taphonomic model of Syme and Salisbury, 2014). The dorsal part of the skeleton was found partially eroded with the exception of the skull, which lay slightly below ground level. Large turtle plastron ele ments were collected near the skull (Fig. 7E). The skull, two dorsal vertebrae, several dorsal rib and gastralia fragments, a partial humerus and osteoderms were collected during the excavation. The remaining part of the quarry was mapped and isolated elements littering the ground were collected.

The M. rex holotype was collected in association with abundant, disarticulated elements from large turtle carapaces, plastrons and vertebrae. The largest turtle elements, including a $25 \mathrm{~cm}$ long hyoplastron associated with the skeleton (Fig. 7E), suggest an in dividual close to $1 \mathrm{~m}$ in body length. Because most of the turtle elements were slightly above the type skeleton of $M$. rex, these elements can be attributed to a subsequent depositional event. Microvertebrate remains are representative of brackish and marine taxa and include elasmobranchs, actinopterygians, dipnoans and rare pterosaur teeth. Bivalves, gastropods, fragmentary echinoids shell and spines, and scaphopods are also abundant.

In terms of relative percentage, fish elements (teeth, scales and centra) represent $71 \%$ of the isolated elements; crocodilian (teeth and osteoderms) 10\%; invertebrates (gastropods, bivalves, and echinoderms) $4 \%$; elasmobranchs $3 \%$; and the remaining $12 \%$ consists of unidentifiable bony elements and teeth. Significantly, several teeth less than $5 \mathrm{~mm}$ in apicobasal length and a $4 \mathrm{~mm}$ wide osteoderm are otherwise morphologically similar to those described for Machimosaurus; the teeth are referred to the latter taxon based on shared presence of blunt apex and anastomosing apicobasal ridges on tooth crown. In addition, a partial dentary with in situ teeth referable to a juvenile individual of Machimosaurus was recovered in association with the type skull of $M$. rex. Prospecting activities in the area revealed the presence of four additional crocodylomorph individuals comparable in size and overall preservation to the $M$. rex holotype within $200 \mathrm{~m}$ from the main quarry.

The lower beds of the Douiret Formation are also rich in megaplant remains, including large gypsified and sporadic hematized trunks reaching $8 \mathrm{~m}$ in length. Remarkable fossil abundance in the area and recurrent tree trunks indicate high rates of sediment supply and accumulation: however, the lack of in situ plant roots and organic components in the sediments combined with gypsified fossils and dolomitized sandstones indicate arid to xeric environments subject to evaporitic conditions. Overall, facies analysis and faunal assemblage are interpreted as a vast lagoonal system with both marine and terrestrial influences.

\section{Systematic paleontology}

Crocodylomorpha Hay, 1930

Thalattosuchia Fraas, 1901

Teleosauridae Saint Hilaire, 1831

Machimosaurus von Meyer, 1837

Machimosaurus rex sp. nov.

(ZooBank code: LSID urn:lsid:zoobank.org:act:1A11E9B9 0B1C 4557 92B7 165168658C17)

(ZooBank code: LSID urn:Isid:zoobank.org:pub:74F1DA00 4482 4398 A69B 144969210627)

Etymology. The species name rex, Latin for "king", refers to its majestic size among known Machimosaurus and all thalattosuchians.

Holotype. ONM NG NG 1-25, 80, 81, and 83-87 (Figs. 2-7D; Table 1).

Locality and horizon. Touil el Mhahir, Tataouine Governorate, Tunisia; Douiret Sand Member, Douiret Formation, Hauterivian, Lower Cretaceous.

Diagnosis. Teleosaurid differing from other species by unique combination of: adult basicranial length $>155 \mathrm{~cm}$ (Fig. 5); rostrum ornamented by densely arranged, parallel longitudinal ridges; orbit elliptical; interorbital space narrow (one fifth length of skull posterior to orbit); anteromedial margin of supratemporal fossae round; frontal not extended anteriorly to orbit and with reduced orbital margin; relatively large maxillary alveoli; anterior dorsal neural spine height less than centrum height; dorsal osteoderms with tightly packed pits that are round centrally and ellipsoid peripherally.

Differential diagnosis. Among the genus Machimosaurus (Fig. 8), M. rex differs from $M$. buffetauti (Fig. 8A) in having relatively larger and more closely spaced alveoli, and in bearing apicobasally aligned enamel ridges immediately adjacent to the apical anastomosed region of crown teeth that are closely packed on both labial and lingual sides; from M. hugii (Fig. 8C) in showing more developed ornamentation on maxillae and nasals, elliptical orbits, narrower interorbital space, and dorsal osteoderms with more closely spaced pits that become more elongate peripherally; from M. mosae (Fig. 8B) in bearing elliptical orbits and shallower and unkeeled 


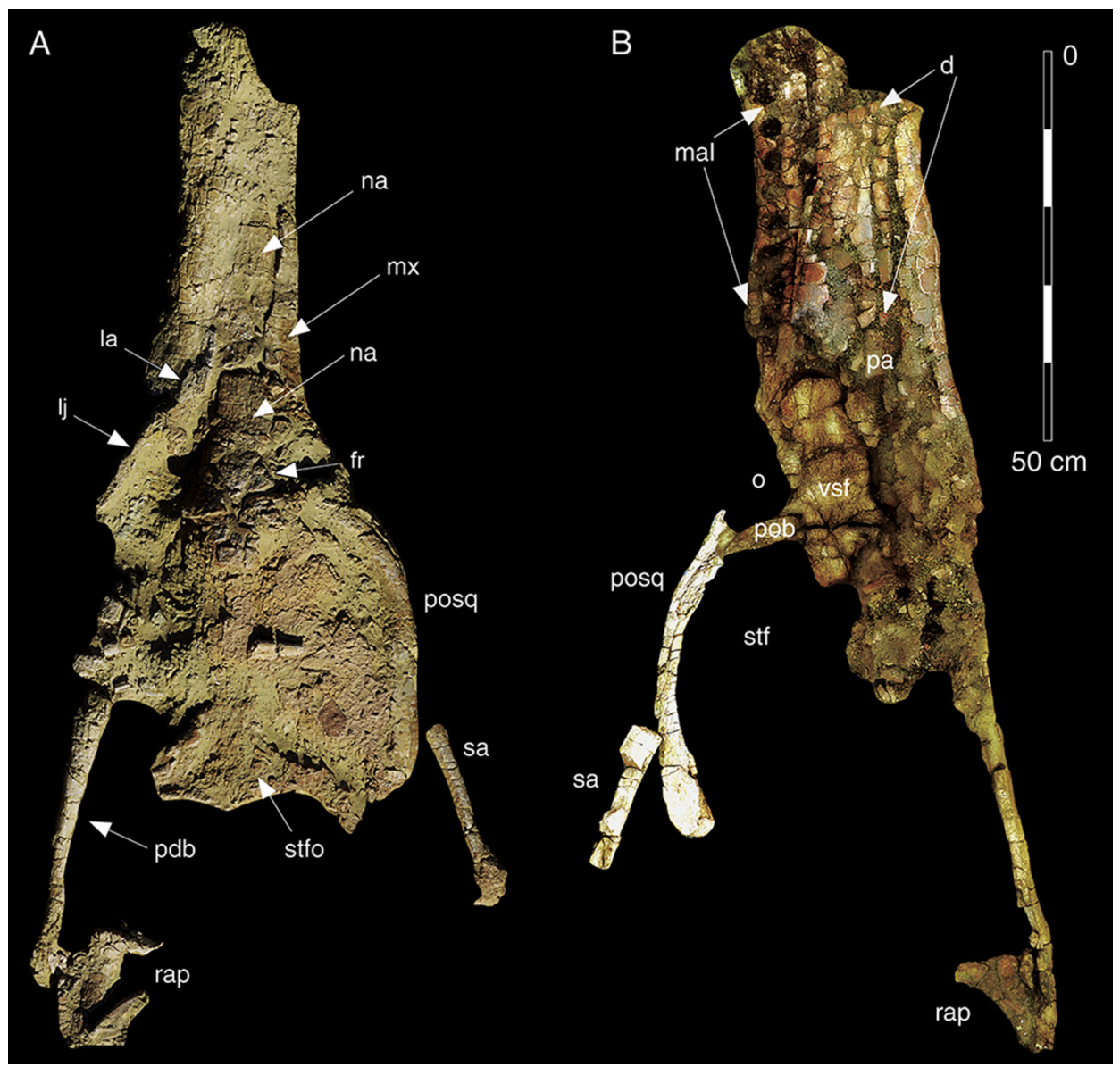

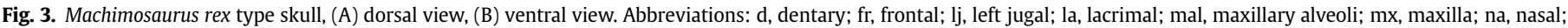
pa, palatal element; pdb, postdentary bones; posq, postorbital-squamosal bar; rap, retroarticular process; sa, surangular; stfo, floor of supratemporal fossa. Scale bar 50 cm.

ventral osteoderms. There is currently no overlapping material between $M$. nowackianus and $M$. rex for a direct morphological comparison. Although stratigraphic placement alone cannot be used as a taxonomic criterion, based on stratigraphic separation between the two type localities of $M$. nowackianus and $M$. rex (the former is Oxfordian Kimmeridigian in age, see Young et al., 2014b), we consider likely these two African species as distinct.

\section{Description of Machimosaurus rex type specimen}

\subsection{Skull and mandible (Figs. 3-7A)}

The anterior end of the snout is missing. Based on comparison with other specimens of Machimosaurus (Hua, 1999; Martin and Vincent, 2013; Young et al., 2014a,b), we estimate that approximately posterior two thirds of the maxillae are intact. The pre served parts are ornamented with a dense pattern of lightly developed longitudinal ridges (Fig. 5A). Eight alveoli are preserved in the right maxilla (Fig. 5C). They are relatively large, their diameter being up to one sixth of snout width, and are closely spaced (Martin and Vincent, 2013; Young et al., 2014b). The interalveolar space is regular, as in the mid and posterior part of the maxilla of $M$. hugii and M. mosae. The nasal is subtriangular in dorsal view and ornamented by a finely developed pattern of longitudinal ridges. It does not reach the narial region anteriorly. The periorbital region is poorly preserved, with only fragmentary prefrontals and lacrimals present. Nevertheless, the preserved outline indicates elliptical orbits, more like that in $M$. buffetauti, differing from the more quadrangular shape observed in both M. hugii and M. mosae (Young et al., 2014b). The lateral margins of the orbits are at the level of the anteromedial corners of the supratemporal fossae, relatively much closely placed than in $M$. hugii (Young et al., 2014b, fig. 41). The nasofrontal suture is at the level of the anterior margin of the orbit. The anterior end of the dorsal interfenestral bar is preserved, but most of the bar, including the parietal, is lost. The anterior margin of the supratemporal fossa is gently rounded. The posterior floor of the supratemporal fossae is partially preserved. The postorbital is robust and elongate posteriorly. Only the lateral part of both squamosals is preserved. The occipital region of the skull is pre served in numerous fragments. Nevertheless, the occipital condyle was preserved in situ, allowing an accurate estimation of the pre served basicranial length. The occipital condyle (Fig. 7A) consists exclusively of the basioccipital, as in other species of Machimosau rus (Young et al., 2014b). The posterior ends of both dentaries are preserved in articulation with the postdentary bones. The external mandibular fenestra is elongate anteroposteriorly. Both the left and right surangulars are articulated with the glenoid region. The an gulars are in fragments. The retroarticular processes are elongate posteriorly and triangular in dorsal view. The teeth (Fig. 6) have several diagnostic features for Machimosaurus (Young et al., 2014c). The relatively low crowns are blunt apically and slightly curved apicodistally. No carinae are present, suggesting that all preserved teeth belong to the posterior half of the tooth row. The crowns are ornamented with tightly packed ridges oriented apicobasally. As in M. hugii, and differing from M. buffetauti (Young et al., 2014c), these 


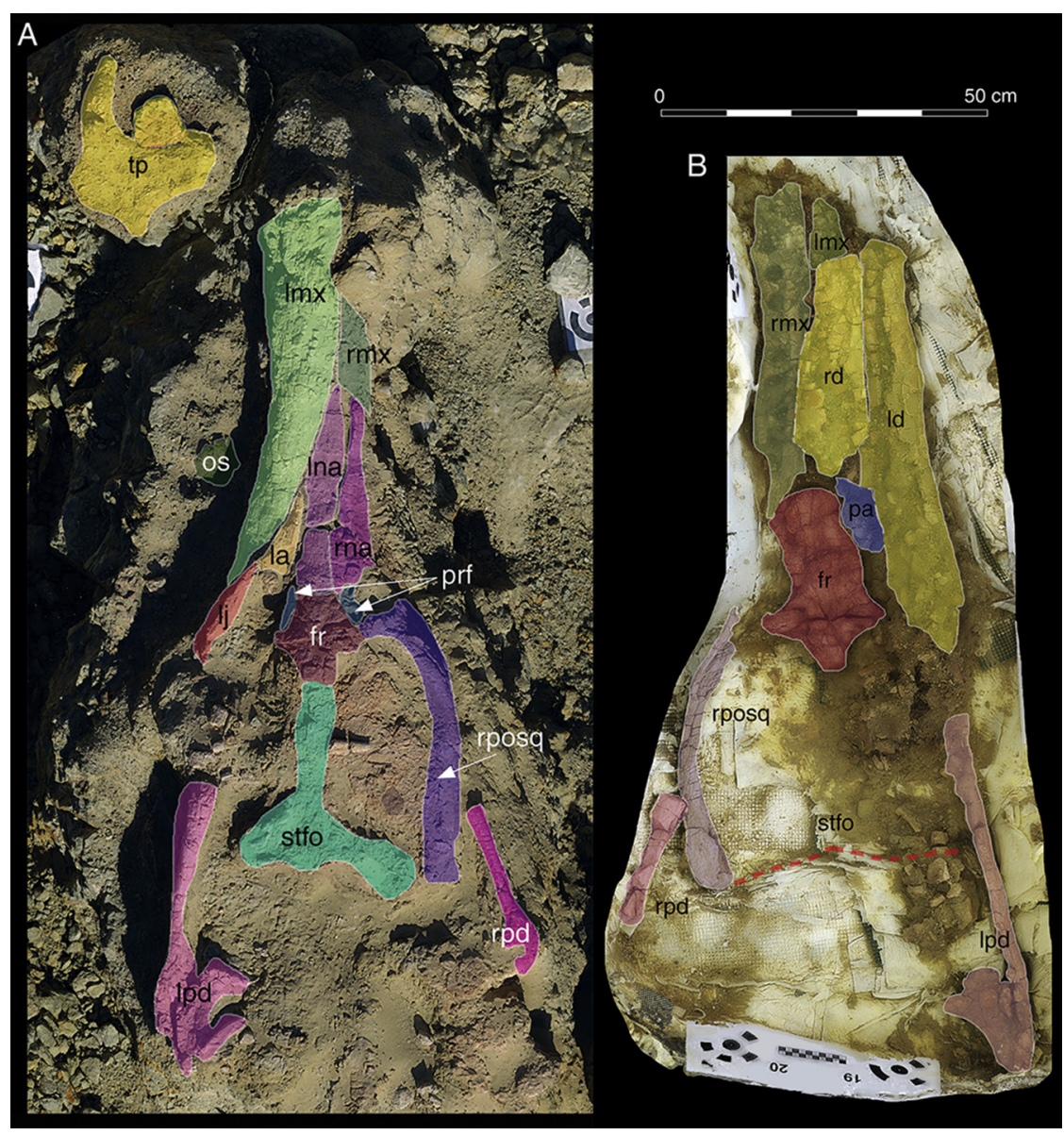

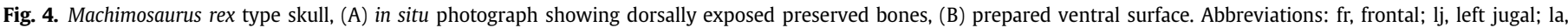

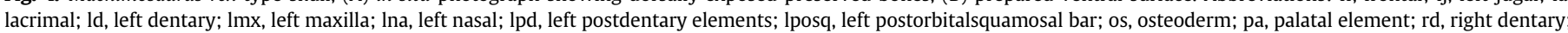

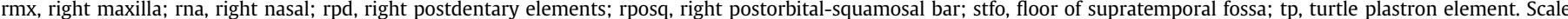
bar $50 \mathrm{~cm}$.
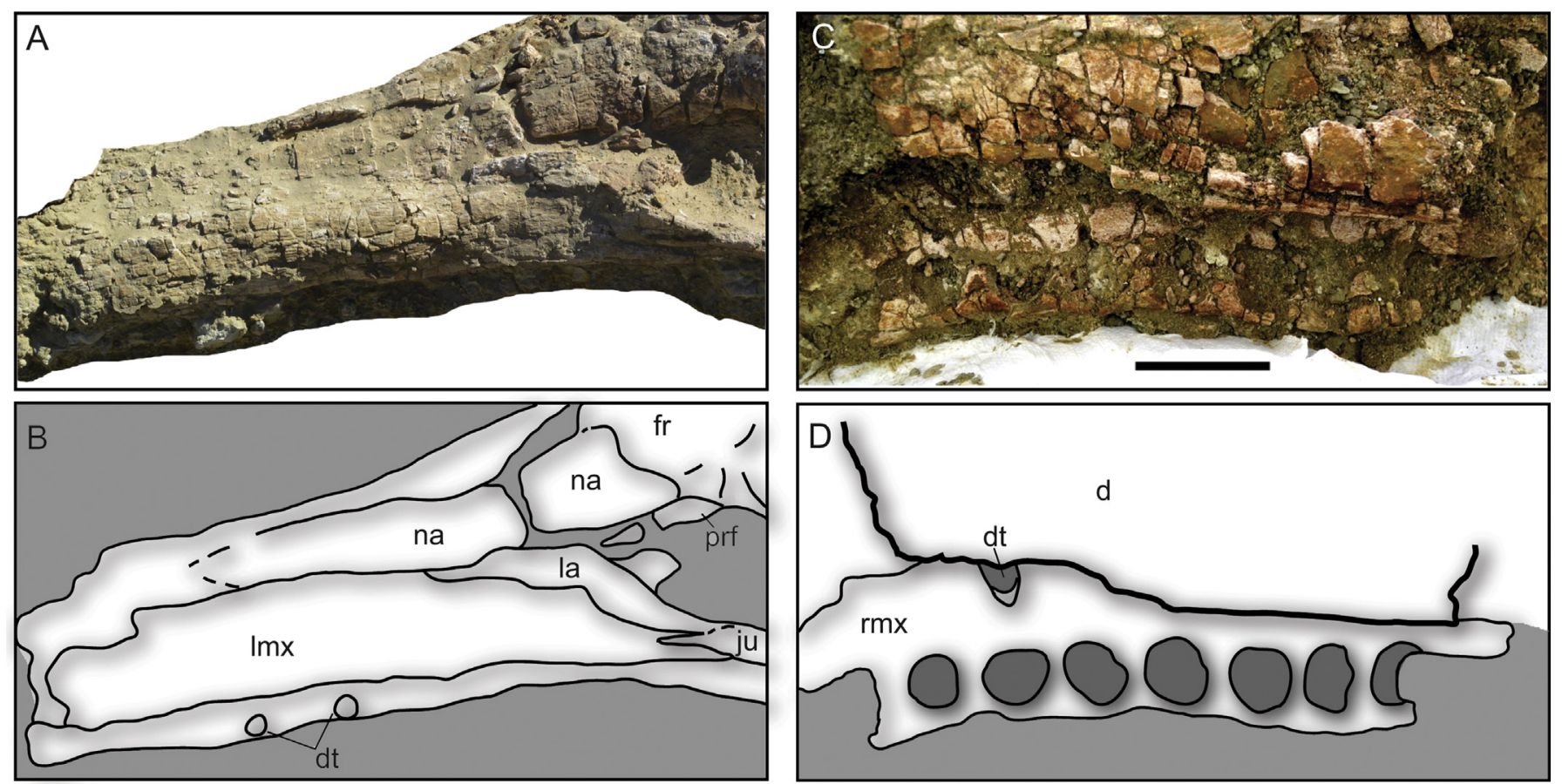

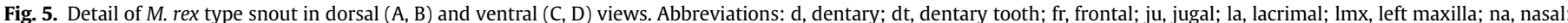
prf, prefrontal; rmx, right maxilla. Scale bar in $C 5 \mathrm{~cm}$. 

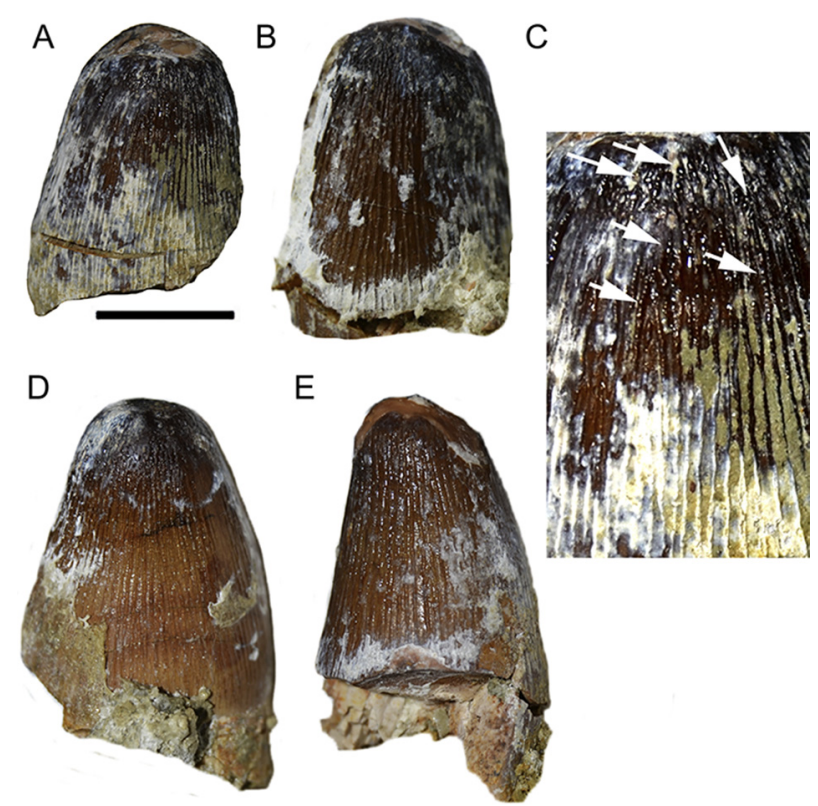

Fig. 6. Dentition of M. rex type. Isolated tooth crowns in labial (A, D) and lingual (B, E) views; (C) detail of enamel close to apex. Arrows indicate tubercle-like ornamentation of ridges. Scale bar $5 \mathrm{~cm}$.
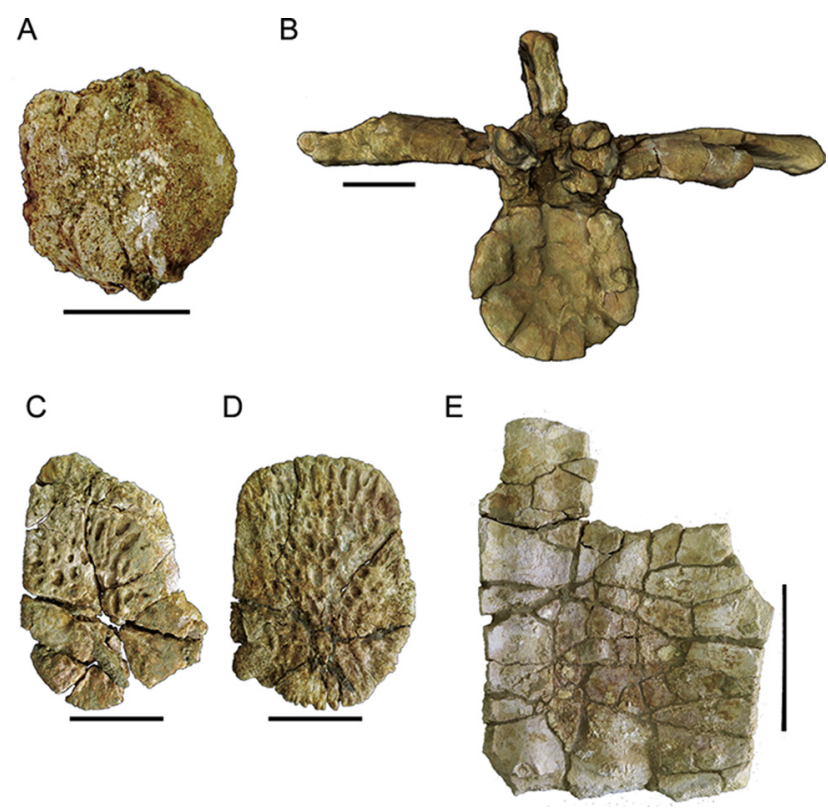

Fig. 7. Skeletal anatomy of $M$. rex sp. nov. type specimen and associated turtle remains. (A) Occipital condyle in dorsal view. (B) Anterior dorsal vertebra in anterior view. (C D) Osteoderms in dorsal views. (E) Turtle hyoplastron in visceral view. Scale bars A D $5 \mathrm{~cm}$; E $10 \mathrm{~cm}$.

ridges are closely packed on both labial and lingual sides of the crown. The ridges are irregularly undulated, but not producing distinct pseudo tubercles as in M. hugii (Young et al., 2014a,b). The ridges are anastomosed in the apical third of the crowns, forming a complex network as in other species of Machimosaurus. Most teeth show a distinct (macroscopical) apical wear.

\subsection{Postcranial skeleton (Figs. 2, 7B-D)}

The cervical series is poorly preserved. Few fragments of the atlas axis complex were recovered adjacent to the occipital region of the skull. Two well preserved anterior dorsal vertebrae have massive centra that are as wide as tall in anterior view (Fig. 7B). The articular facet of the centra are subcircular and moderately concave. The lateral surfaces of the centra are both dorsoventrally and anteroposteriorly concave, due to the marked lateral rims of the articular facets. The neural arch is transversely wide and low dorsoventrally and has closely joined diapophyses and parapophyses that are oriented subhorizontally. The parapophyses extend laterally to half the extent of the diapophyses, with their articular surfaces facing posterolaterally. The dorsal surface of the transverse process is anteroposteriorly convex. The ventrolateral surfaces of the neural arches are moderately concave centrally. The neurocentral suture is obliterated, suggesting a mature individual. The zygapophyses are stout and moderately projected anteroposteriorly, being placed lateral to the neural canal and medial to the centrum outline in anterior/posterior views. The neural spine is robust, lower dorsoventrally than the height of the centrum and moderately expanded transversally at its apex. Several dorsal ribs and gastralia were found in articulation, although extremely fragmented.

Appendicular elements include fragments of the left forelimb, interpreted as the humeral shaft, and worn elements that, based on in situ placement posterior to the dorsal ribs series, are interpreted as belonging to the hindlimb.

\subsection{Osteoderms (Fig. 7C, D)}

Isolated osteoderms were found adjacent to the lower jaws. As the skull is turned backward relative to the presacral vertebral column, the osteoderms are interpreted as pertaining to the dorsal region. The osteoderms are quadrangular, with poorly developed anterolateral processes. Osteoderm ornamentation includes a tightly packed pattern of rounded pits in the central part of the dorsal surface, surrounded peripherally by radially elongate pits that reach the margin of the osteoderm; this pitting pattern differs from the more irregular pattern reported by Young et al. (2014b) for Machimosaurus hugii. Furthermore, none of the recovered osteoderms bears the marked thickening and the distinct keel both diagnostic of Machimosaurus mosae (Hua, 1999).

\section{Results}

\subsection{Phylogenetic analysis}

The MCCT of Thalattosuchia resulted by the Bayesian phylogenetic analysis (Fig. 9) agrees in overall topology with previous analyses of the same dataset using parsimony as tree search strategy (e.g., Young 2014). The analysis strongly supports the monophyly of Machimosaurus (posterior probability: 97\%) and the inclusion of the new Tunisian taxon in that genus. Machimosaurus buffetauti resulted the basalmost member of the genus, excluded from the clade including $M$. rex and the other European species (posterior probability: 63\%). The analysis therefore supports the distinction of $M$. buffetauti from other Machimosaurus suggested by Young et al.(2014a). Cladogenetic timing estimated by the Bayesian analysis places the divergence of the lineage leading to $M$. rex from the other Machimosaurus lineages at about 155 Mya.

\section{Size of Machimosaurus rex}

\subsection{Skull length}

The skull of the type specimen of M. rex lacks the anterior end of maxillae and the premaxillae. The basicranial length of the preserved skull is $114 \mathrm{~cm}$, the length of the preserved skull from the 

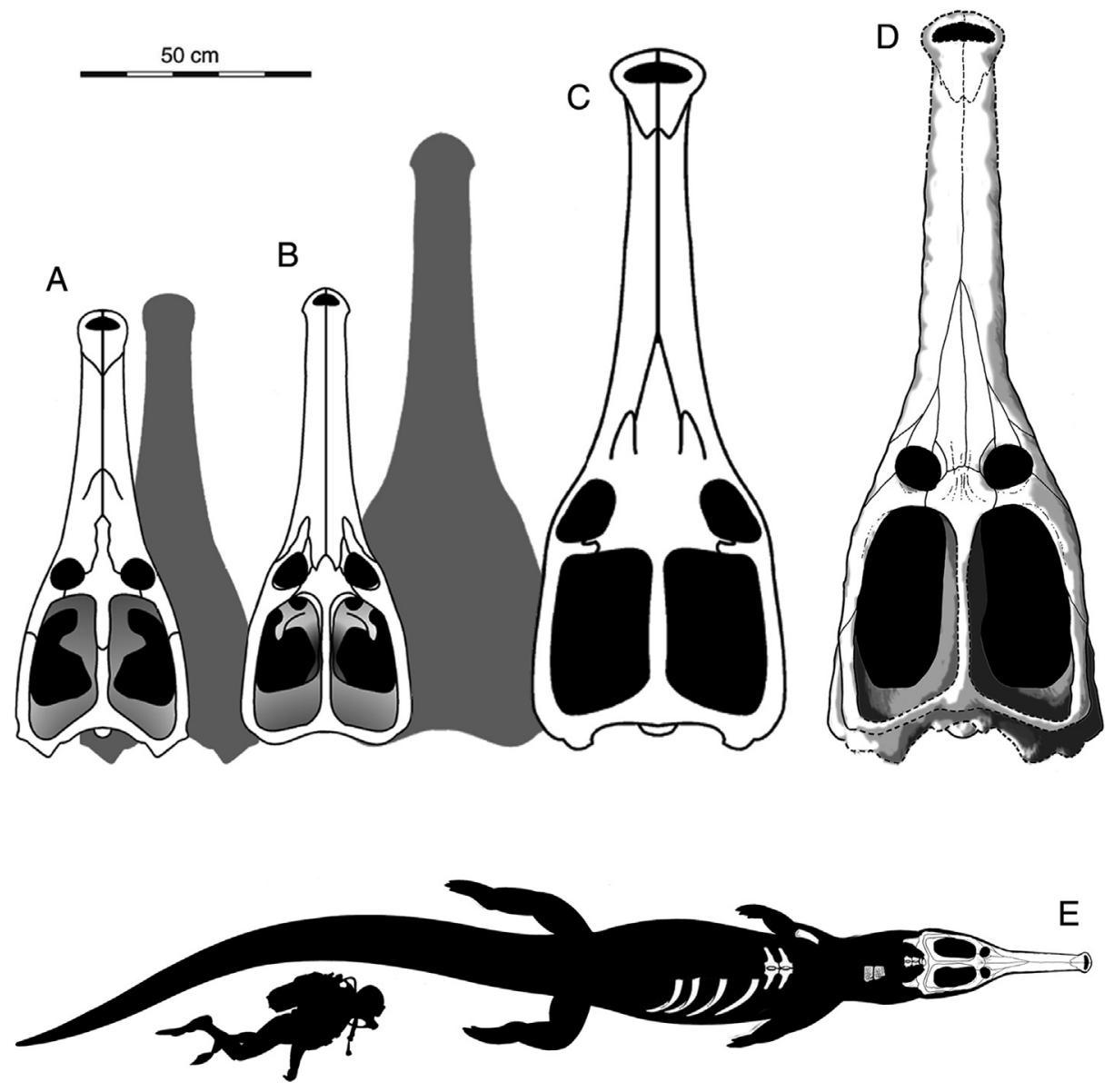

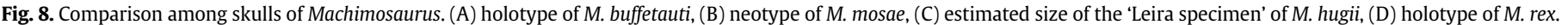

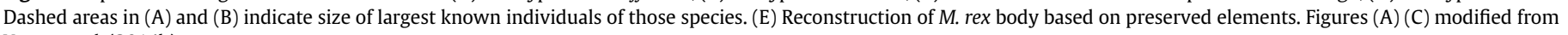
Young et al. (2014b).

anterior end to the left mandibular glenoid is $134 \mathrm{~cm}$. The length of the skull from occiput to the anterior end of the orbits ('post snout' length) is $65 \mathrm{~cm}$. In a complete skull of $M$. buffetauti with a basicranial length of $93.5 \mathrm{~cm}$ (Kimmeridgian, Germany; Martin and Vincent, 2013; Fig. 8A), the equivalent part of the skull is $39 \mathrm{~cm}$ long ( $42 \%$ of basicranial length). In other specimens of Machimo saurus, the snout length of the skull is approximately $58 \%$ of the basicranial length, a value that is considered as an autapomorphy of Machimosaurus (Hua, 1999; Young et al., 2014b; Fig. 8B). That implies a 'post snout' length of about $42 \%$ of the skull length in this taxon (see also Martin and Vincent (2013), table 6). Assuming that the proportions of the complete skull of $M$. rex holotype were comparable to those observed in other Machimosaurus species, we estimate a minimum total basicranial length for the Tunisian taxon of $155 \mathrm{~cm}$. Prior to this discovery, the largest size of Machimosaurus was based on a fragmentary skull of $M$. hugii (the "Leira specimen" of Young et al. 2014b, see Krebs (1967), Fig. 8C) with the basicranial length estimated between $141 \mathrm{~cm}$ (Hua, 1999) and $149 \mathrm{~cm}$ (Young et al., 2014b). Nevertheless, the "Leira specimen" lacks most of the orbital and temporal regions, and no measurements of the preserved elements are available, thus preventing any testable estimation of its actual size (see Krebs, 1967).

A comparison between the size of the alveoli in $M$. rex type specimen and other Machimosaurus individuals further supports the giant size of the Tunisian taxon. In the skull of $M$. buffetauti type specimen (Martin and Vincent, 2013), the mesiodistal diameter of the alveoli at mid length of the maxilla is between 15 and $18 \mathrm{~mm}$.
In the neotype of $M$. mosae, the middle maxillary alveoli diameter ranges between 18 and $25 \mathrm{~mm}$ (Hua, 1999). In the type specimen of $M$. rex, the mesiodistal diameter of the middle maxillary alveoliranges between 30 and $43 \mathrm{~mm}$, a value $200 \%$ or more than those of $M$. buffetauti holotype, and about 166-173\% larger than those in the $M$. mosae neotype. The latter range confirms that the basicranial length of the Tunisian specimen is at least $166 \%$ larger than that of the $M$. mosae neotype. Since the type skull of $M$. rex is also estimated about $165-170 \%$ the size of the M. buffetauti type skull (Martin and Vincent, 2013), the Tunisian species shows proportionally larger alveoli than in M. buffetauti.

\subsection{Total body length}

Young et al. (2014b) used the well preserved neotype specimen of $M$. mosae to estimate the total body length of various specimens of Machimosaurus from their basicranial lengths, assuming a body length to basicranial length ratio of about 6.22. Assuming isometry among the various Machimosaurus individuals, and using the same relationships of Young et al. (2014b), the total body length of M. rex type is estimated at least as $9.6 \mathrm{~m}$. Compared to the neotype of M. mosae, the alveoli in M. rex holotype are about 166\% larger than the same element in the French specimen (Hua, 1999). Therefore, assuming isometry in body proportions, based on both cranial and dental comparisons with the best preserved specimen of Machimosaurus mosae (Hua, 1999) the total body length of the Tunisian 
Table 1

Selected measurements of Machimosaurus rex type specimen.

\begin{tabular}{|c|c|c|c|}
\hline & & \multicolumn{2}{|c|}{ Measurements $(\mathrm{cm})$} \\
\hline \multicolumn{4}{|l|}{ Skull } \\
\hline \multicolumn{2}{|c|}{ Preserved basicranial length } & \multicolumn{2}{|l|}{114} \\
\hline \multicolumn{2}{|c|}{$\begin{array}{l}\text { Left side, from preserved anterior } \\
\text { end to mandibular glenoid }\end{array}$} & \multicolumn{2}{|l|}{134} \\
\hline \multicolumn{2}{|c|}{$\begin{array}{l}\text { Right side, distance from mandibular } \\
\text { glenoid to anterior orbit }\end{array}$} & \multicolumn{2}{|l|}{64} \\
\hline \multicolumn{2}{|c|}{ Width of snout anterior to orbits } & \multicolumn{2}{|l|}{25} \\
\hline \multicolumn{2}{|c|}{ Internal supratemporal fenestra length } & \multicolumn{2}{|l|}{33} \\
\hline \multicolumn{2}{|c|}{ Distance between five maxillary alveoli } & \multicolumn{2}{|l|}{22} \\
\hline \multicolumn{2}{|c|}{ Estimated total length of maxillary tooth row (range) } & \multicolumn{2}{|l|}{$80-97$} \\
\hline \multicolumn{2}{|c|}{ Preserved snout length } & \multicolumn{2}{|l|}{49} \\
\hline \multicolumn{2}{|c|}{ Postorbital skull length } & \multicolumn{2}{|l|}{65} \\
\hline \multicolumn{2}{|c|}{ Interorbital width } & \multicolumn{2}{|l|}{11.5} \\
\hline \multicolumn{2}{|c|}{ Occipital condyle width } & \multicolumn{2}{|l|}{6.2} \\
\hline \multicolumn{4}{|l|}{ Postcranial } \\
\hline \multicolumn{2}{|c|}{ Anterior dorsal centrum height } & \multicolumn{2}{|l|}{8.5} \\
\hline \multicolumn{2}{|c|}{ Anterior dorsal vertebra total height } & \multicolumn{2}{|l|}{17.6} \\
\hline \multicolumn{2}{|c|}{ Anterior dorsal vertebra width across diapophyses } & \multicolumn{2}{|l|}{24.3} \\
\hline Maxillary Alveoli ${ }^{\mathrm{a}}$ & MD & & LL \\
\hline 1 & 29.6 & & 35.2 \\
\hline 2 & 29.5 & & 28.8 \\
\hline 3 & 34.4 & & 28.2 \\
\hline 4 & 32.6 & & 26.1 \\
\hline 5 & 33.6 & & 29.9 \\
\hline 6 & 43.4 & & 34.7 \\
\hline 7 & 38.9 & & 29.9 \\
\hline 8 & n.d. & & 32.4 \\
\hline
\end{tabular}

MD, mesiodistal diameter; LL, labiolingual diameter, in $\mathrm{mm}$.

a Numeration refers to position along the preserved maxilla and not to the inferred position in the complete tooth row.

individual is estimated at about $10 \mathrm{~m}$ (166\% of $6 \mathrm{~m}$, see Young et al., 2014b; Fig. 8E).

\section{Discussion}

\subsection{Hypothetical lifestyle}

The skull of $M$. rex bears a platyrostral snout, longitudinally oriented ornamentations on the skull roof, elongate subrectangular supratemporal fossae and blunt crowned teeth with anastomosed apical enamel ornamentation (Figs. 1, 2), all synapomorphies of derived teleosaurids (Young et al., 2014b). With the skull length up to $160 \mathrm{~cm}$ and an estimated body length around $10 \mathrm{~m}$ (Fig. 8E), the new Tunisian species is the largest known thalattosuchian, and was the largest known crocodylomorph from the Triassic until the Aptian Albian (see Young et al., 2014b, Johnson et al., 2015). As in other Machimosaurus (in particular, M. hugii, Young et al., 2014b,c), the low crowned, sub globidont dentition of $M$. rex supports a generalist durophagous feeding ecology. The abundance of turtle remains in the $M$. rex quarry, including large bodied forms with length approaching $1 \mathrm{~m}$, suggests that chelonians were a significant part of the diet also in the Tunisian taxon.

Krebs (1967) and Hua (1999) discussed the hypothetical life styles of $M$. hugii and M. mosae respectively (see also the review by Young et al., 2014b). The former was interpreted as well adapted to an open sea environment, whereas the latter resulted better adapted to high energy, coastal conditions. Based on extant ana logues among crocodilians showing an inverse relationships be tween dermal ornamentation and aquatic adaptation, the relatively reduced ornamentation in both skull roof and osteoderms of Machimosaurus hugii has been suggested as additional functional adaptation to a pelagic lifestyle (Young et al., 2014b). Similarly, the thick and keeled ventral osteoderms of $M$. mosae are interpreted as adaptations to a high energy/turbulent environment (Hua, 1999;
Young et al., 2014b). In M. rex, both skull roof ornamentation and extent of pitting on the osteoderms are more developed than in $M$. hugii. The relatively shallower osteoderms lacking a keel suggest that the Tunisian species was not adapted to a high energy environment as that inferred for $M$. mosae. This interpretation is consistent with the paleoecology of the M. rex type locality (see above) indicating a lagoonal environment with significant terres trial influences.

In analogy with modern semi aquatic crocodilians, we suggest that $M$. rex was an ambush predator that preyed on both aquatic and terrestrial vertebrates. Since Machimosaurus bite marks on a sauropod dinosaur bone are already known (Young et al., 2014b), we predict that $M$. rex included mid to large bodied dinosaurs in its diet.

\subsection{Implications for teleosaurid extinction}

Unlike their survival into the Cretaceous of southern Tethys, teleosaurids did not cross the J $\mathrm{K}$ boundary in the northern realm (Young et al., 2014a,b). The Late Jurassic species of Machimosaurus occur from Portugal to Germany to Ethiopia in lagoonal to shallow marine settings (Young et al., 2014b). These environmental conditions existed well into Cretaceous times in southern Tunisia, where lagoonal to tidal flats deposits straddle the $\mathrm{J} \mathrm{K}$ transition and dominate the Lower Cretaceous sedimentary successions (Benton et al., 2000; Barale and Ouaja, 2002; Ouaja et al., 2004; Anderson et al., 2007; Ouaja et al., 2011; Fanti et al., 2012). Conversely, the end Jurassic transition in Europe is characterized by rapid climatic oscillations (alternation of 'greenhouse' conditions and cooling events) and concomitant extension of pelagic environments with dramatic loss of shallow marine and coastal ecosystems (Adatte et al., 1996; Cecca, 1999; Cecca et al., 2001; Dromart et al., 2003; Lécuyer et al., 2003; Cecca et al., 2005; Husinec and Jelaska, 2006; Ruban, 2011; Martin Garin et al., 2012). Reduction of these habitats most likely resulted in local extinction of teleosauroids across the J $\mathrm{K}$ boundary of Europe. Among macropredatory marine reptiles, as many as nine ichthyosaurian, three plesiosaurian and at least four metriorhynchoid lineages crossed the $\mathrm{J} \mathrm{K}$ boundary, and morphological disparity of these clades maintained the preboundary levels through Early Cretaceous (Fischer et al., 2012, 2013, 2014; Benson and Druckenmiller, 2014; Young et al., 2014a; Chiarenza et al., 2015). Our study adds teleosauroids to the list of the reptilian lineages that crossed the Jurassic Cretaceous boundary.

\section{Conclusion}

Machimosaurus rex sp. nov. is based on the articulated skeleton of a giant crocodylomorph from the Hauterivian of Tunisia. This taxon represents the first indisputable Cretaceous teleosauroid, and the first member of this clade from Africa based on well preserved remains. With a basicranial length approaching $160 \mathrm{~cm}$ (and a partial skeleton indicating a total body length around $10 \mathrm{~m}$ ), M. rex is the largest known thalattosuchian. Both paleoecological data and morphological features suggest that this species was an ambush generalist predator with an ecology comparable to extant semiaquatic crocodilians. The discovery of $M$. rex falsifies a global mass extinction event at the $\mathrm{J} \mathrm{K}$ transition (i.e., teleosauroid extinction), thereby highlighting the problem of sampling bias in the reconstruction of large scale patterns in the geological record. The new Tunisian teleosaurid points to a conservative interpretation of faunal turnovers during the $\mathrm{J} K$ transition: local extinction events triggered by regional ecological factors and survival of widely distributed and eurytypic forms by means of habitat tracking. 


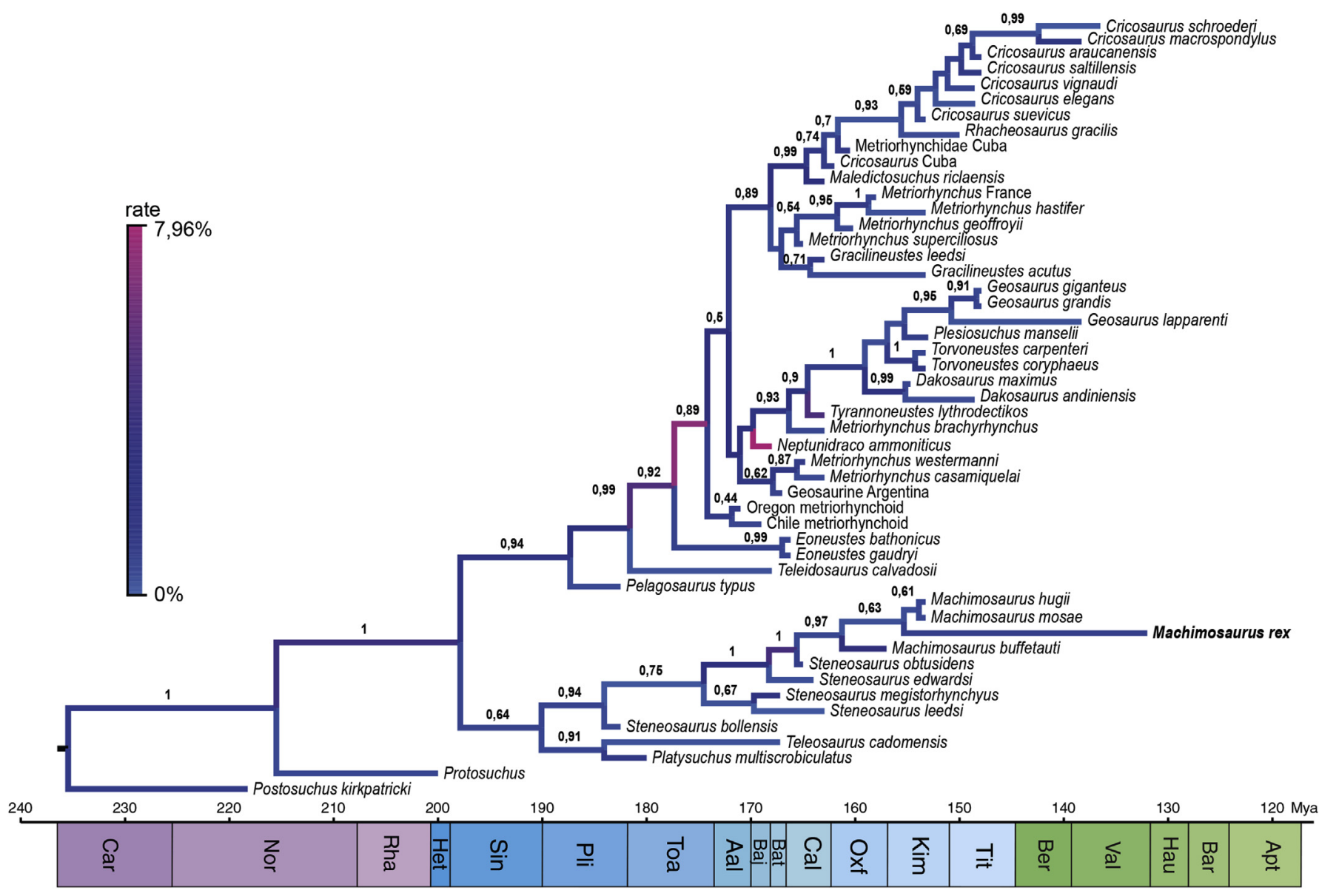

Fig. 9. Maximum Clade Credibility Tree of thalattosuchian evolution with divergence rates indicated by colored branches. Values at nodes indicate posterior probability values $>0.5$. (For interpretation of the references to colour in this figure legend, the reader is referred to the web version of this article).

\section{Acknowledgements}

This research was supported by the National Geographic Society (grant 9586 14), Museo Geologico G. Capellini (Bologna) and Office National des Mines (Tunis). This manuscript benefited from discussion with A.R. Fiorillo (Perot Museum of Nature and Science, Dallas, U.S.A.). We thank S. Hua, M. Young and Editor in Chief E. Koutsoukos for detailed revisions that improved the quality of the manuscript. The Machimosaurus rex holotype was discovered by FM during prospecting activities led by FF, and excavated by a team including FF, JD, LC, AC and FM. The specimen was prepared in Tunis by FF, FM, JD, LC, TM, and MC. AC and FF conceived and wrote the manuscript, performed the analyses and prepared the figures. TM, LC, MC, JD and FM helped draft the manuscript and prepare the figures. Skeletal reconstructions of M. rex are by M. Auditore. We thank the other members of the 2014 Italian -Tunisian palaeontological expedition in the Tataouine Governa torate, in particular, H. Aljane, M. Hassine, L. Angelicola, A. Bacchetta, S. Cafaggi, J. Carlet and G. Mignani. This study is dedi cated to the memory of Mounir Riahi, curator of the Musée de l'Office National Des Mines.

\section{References}

Adatte, T., Stinnesbeck, W., Remane, J., Hubberten, H., 1996. Paleoceanographic changes at the Jurassic Cretaceous boundary in the Western Tethys, north$\begin{array}{lllll}\text { eastern } & \text { Mexico. Cretaceous } & \text { Research } & \text { 17, } & 671\end{array}$ Agassiz, L., 1833. Recherches sur les poissons fossils. Petitpierre, Neuchâtel et Soleure.
Anderson, P.E., Benton, M.J., Trueman, C.N., Paterson, B.A., Cuny, G., 2007. Palaeoenvironments of vertebrates on the southern shore of Tethys: the nonmarine Early Cretaceous of Tunisia. Palaeogeography, Palaeoclimatology, Palaeoecology 243, 118131.

Bakker, R.T., 1978. Dinosaur feeding behaviour and the origin of flowering plants. Nature 274, 661663 .

Bakker, R.T., 1998. Dinosaur mid-life crisis: the Jurassic-Cretaceous transition in Wyoming and Colorado. New Mexico Museum of Natural History Bulletin 14, 6777.

Bambach, R.K., 2006. Phanerozoic biodiversity mass extinctions. Annual Review of Earth and Planetary Science Letters 34, 127155.

Barale, G., Ouaja, M., 2002. La biodiversité végétale des gisements d'âge Jurassique supérieur Crétacé inférieur de Merbah El Asfer (Sud-Tunisien). Cretaceous Research 23, 707737.

Bardet, N., 1994. Extinction events among Mesozoic marine reptiles. Historical Biology 7, 313324.

Beardsley, P., Torr, P., Zisserman, A., 1996. 3D model acquisition from extended image sequences. Computer Vision ECCV 96, 683695.

Benson, R.B., Butler, R.J., Lindgren, J., Smith, A.S., 2010. Mesozoic marine tetrapod diversity: mass extinctions and temporal heterogeneity in geological megabiases affecting vertebrates. Proceedings. Biological Sciences/The Royal Society 277, 829834 .

Benson, R.B., Druckenmiller, P.S., 2014. Faunal turnover of marine tetrapods during the Jurassic- Cretaceous transition. Biological Reviews Cambridge Philosophical Society 89, 123.

Benton, M.J., 2001. Biodiversity on land and in the sea. Geological Journal 36, 211230.

Benton, M.J., Bouaziz, S., Buffetaut, E., Martill, D., Ouaja, M., Soussi, M., Trueman, C., 2000. Dinosaurs and other fossil vertebrates from fluvial deposits in the Lower Cretaceous of southern Tunisia. Palaeogeography, Palaeoclimatology, Palaeoecology 157, 227246.

Bodin, S., Petitpierre, L., Wood, J., Elkanouni, I., Redfern, J., 2010. Timing of early to mid-cretaceous tectonic phases along North Africa: new insights from the Jeffara escarpment (Libya Tunisia). Journal of African Earth Sciences 58, 489506.

Brown, B., 1934. A change of names. Science 79, 80. 
Cau, A., 2014. The affinities of 'Steneosaurus barettoni' (Crocodylomorpha, Thalattosuchia), from the Jurassic of Northern Italy, and implications for cranial evolution among geosaurine metriorhynchids. Historical Biology 26, 433440.

Cecca, F., 1999. Palaeobiogeography of Tethyan ammonites during the Tithonian (latest Jurassic). Palaeogeography, Palaeoclimatology, Palaeoecology 147, 137.

Cecca, F., Savary, B., Bartolini, A., Remane, J., Cordey, F., 2001. The Middle JurassicLower Cretaceous Rosso Ammonitico succession of Monte Inici (Trapanese domain, western Sicily): sedimentology, biostratigraphy and isotope stratigraphy. Bulletin De La Societé Géologique De France 172, 647660.

Cecca, F., Martin Garin, B., Marchand, D., Lathuiliere, B., Bartolini, A., 2005. Paleoclimatic control of biogeographic and sedimentary events in Tethyan and peri-Tethyan areas during the Oxfordian (Late Jurassic). Palaeogeography, Palae-oclimatology, Palaeoecology 222, 1032.

Chatterjee, S., 1985. Postosuchus, a new thecodontian reptile from the Triassic of Texas and the origin of Tyrannosaurs. Philosophical Transaction of the Royal Society B: Biological Sciences 309 (1139), 395460.

Chiarenza, A.A., Foffa, D., Young, M.T., Insacco, G., Cau, A., Carnevale, G., Catanzariti, R., 2015. The youngest record of metriorhynchid crocodylomorphs, with implications for the extinction of Thalattosuchia. Cretaceous Research 56, 608616.

Cuny, G., Ouaja, M., Srarfi, D., Schmitz, Buffetaut, E., Benton, M., 2004. Fossil Shark from the Early Cretaceous of Tunisia. Revue de Paléobiologie, Geneve 9,

pp. 127142.

Cuny, G., Cobbett, A.M., Meunier, F.J., Benton, M.J., 2010. Vertebrate microremains from the Early Cretaceous of southern Tunisia. Geobios 43, 615628

Dellaert, F., Seitz, S., Thorpe, C., Thrun, S., 2000. Structure from motion without correspondence. In: Conference on IEEE Hilton Head Island, pp. 557564.

Dromart, G., Garcia, J.P., Picard, S., Atrops, F., Lécuyer, C., Sheppard, S.M.F., 2003. Ice age at the Middle Late Jurassic transition? Earth and Planetary Science Letters

$213,205220$.

Drummond, A.J., Suchard, M.A., Xie, D., Rambaut, A., 2012. Bayesian phylogenetics with BEAUti and the BEAST 1.7. Molecular Biology and Evolution 29, 19691973.

Engel, J., Schops, T., Cremers, D., 2014. LSD-SLAM: large-scale direct monocular SLAM. Computer Vision ECCV 2014 (8690), 834849.

Fanti, F., Contessi, M., Franchi, F., 2012. The "Continental Intercalaire" of southern Tunisia: stratigraphy, paleontology, and paleoecology. Journal of African Earth Sciences 73 74, 123.

Fanti, F., Cau, A., Hassine, M., Contessi, M., 2013. A new sauropod dinosaur from the Early Cretaceous of Tunisia with extreme avian-like pneumatization. Nature Communications 4, 2080.

Fanti, F., Cau, A., Cantelli, L., Hassine, M., Auditore, M., 2015. New information on Tataouinea hannibalis from the Early Cretaceous of Tunisia and implications for the Tempo and Mode of Rebbachisaurid Sauropod Evolution. PLoS One 10, e0123475.

Fischer, V., Maisch, M.W., Naish, D., Kosma, R., Liston, J., Joger, U., Kruger, F.J., Perez, J.P., Tainsh, J., Appleby, R.M., 2012. New ophthalmosaurid ichthyosaurs from the European Lower Cretaceous demonstrate extensive ichthyosaur survival across the Jurassic-Cretaceous boundary. PLoS One 7, e29234.

Fischer, V., Appleby, R.M., Naish, D., Liston, J., Riding, J.B., Brindley, S., Godefroit, P., 2013. A basal thunnosaurian from Iraq reveals disparate phylogenetic origins

for Cretaceous ichthyosaurs. Biology Letters 9, 20130021.

Fischer, V., Bardet, N., Guiomar, M., Godefroit, P., 2014. High diversity in cretaceous ichthyosaurs from Europe prior to their extinction. PLoS One 9, e84709.

Fraas, E., 1901. Die Meerkrokodile (Thalattosuchia n. g.) eine neue sauriergruppe de Juraformation. Jahreshefte des Vereins für vaterl€andische Naturkunde in

Württemberg 57, 409418.

Gasparini, Z., Fernandez, M., Spalletti, L., Matheos, S., Cocca, S., 2004. Reptiles marinos neuquinos en la transicion Jurasico-Cretacico. Ameghiniana 41, 69R.

Haming, K., Peters, G., 2010. The structure-from-motion reconstruction pipeline a survey with focus on short image sequences. Kybernetika 46, 926937.

Hay, O.P., 1930. Second Bibliography and Catalogue of the Fossil Vertebrata of North America, vol. 2. Carnegie Institute Washington, Washington DC.

Hua, S., 1999. Le Crocodilien Machimosaurus mosae (Thalattosuchia, Teleosauridae) du Kimmeridgien du Boulonnais (Pas de Calais, France). Palaeontographica

Abteilung A 252 (4 6), 141170

von Huene, F., 1938. Ein Pliosauride aus Abessinien. Zentralblatt für Mineralogie, Geologie und Palaontologie, B 1938 (10), 370376.

Husinec, A., Jelaska, V., 2006. Relative sea-level changes recorded on an isolated carbonate platform: Tithonian to Cenomanian succession, Southern Croatia.

Journal of Sedimentary Research 76, 11201136.

Johnson, M.M., Young, M.T., Steel, L., Lepage, Y., 2015. Steneosaurus edwardsi

(Thdattosuchia: Teleosauridae), the largest known crocodylomorph of the Middle Jurassic. Biological Journal of the Linnean Society 115 (4), 911918.

Koenderink, J., Doorn, J.J., 1991. Affine structure from motion. Journal of the Optical Society of America 8, 377385

Krebs, B., 1967. Der Jura-Krokodilier Machimosaurus H. v. Meyer. Palaontologische Zeitschrift 41, 4659 .

Kriwet, J., Schmitz, L., 2005. New insight into the distribution and palaeobiology of the pycnodont fish Gyrodus. Acta Palaeontologica Polonica 50, 4956.

Le Loeuff, J., Lang, E., Cavin, L., Buffetaut, E., 2012. Between Tendaguru and Baharia: on the age of the Early Cretaceous dinosaur sites from the Continental Intercalaire and other African formations. Journal of Stratigraphy 36, 486502 .
Le Loeuff, J., Metais, E., Dutheil, D., Rubinos, J., Buffetaut, E., Lafont, F., Cavin, L., Moreau, F., Tong, H., Blanpied, C., Sbeta, A., 2010. An Early Cretaceous vertebrate assemblage from the Cabao Formation of NW Libya. Geological Magazine 147, 750759

Lécuyer, C., Bogey, C., Garcia, J.-P., Grandjean, P., Barrat, J.-A., Floquet, M., Bardet, N. Pereda- Superbiola, X., 2003. Thermal evolution of Tethyan surface waters during the Middle-Late Jurassic: evidence from $\delta 180$ values of marine fish teeth. Paleoceanography 18.

Lee, M.S., Cau, A., Naish, D., Dyke, G.J., 2014. Dinosaur evolution. Sustained miniaturization and anatomical innovation in the dinosaurian ancestors of birds. Science 345,562566

de Loriol, P., 1866. Description des fossiles de l'Oolite Corallienne de l'etage Valanginien et de l'etage Urgonien du Mont-Saleve. In: Favre, E. (Ed.), Recherches geologiques dans les parties de la Savoie, du Piemont et de la Suisse voisines du mont Blanc, pp. 310405.

Lu, P.J., Yogo, M., Marshall, C.R., 2006. Phanerozoic marine biodiversity dynamics in ight of the incompleteness of the fossil record. Proceedings of the National Academy of Sciences of the United States of America 103, 27362739.

Maisey, J.G., 1987. Cranial anatomy of the Lower Jurassic shark Hybodus reticulatus (Chondrichthyes: Elasmobranchii), with comments on Hybodontid systematics. American Museum Novitates 2878, 139.

Martin-Garin, B., Lathuiliere, B., Geister, J., 2012. The shifting biogeography of reef corals during the Oxfordian (Late Jurassic). A climatic control? Palaeogeography,

Palaeoclimatology, Palaeoecology 365 366, 136153.

Martin, J.E., Vincent, P., 2013. New remains of Machimosaurus hugii von Meyer,

1837Crocodilia, Thalattosuchia) from the Kimmeridgian of Germany. Fossil Record 16, 179196.

Martin, J.E., Vincent, P., Falconnet, J., 2015. The taxonomic content of Machimosaurus (Crocodylomorpha, Thalattosuchia). Comptes Rendus Palevol 14 (4), 305 310. von Meyer, C.E.H., 1837. Mitteilungen, an Professor Bronn gerichtet. Neues Jahrbuch

für Mineralogie, Geologie. Geognosie und Petrefaktenkunde 4, 413 418. Newham, E. Benson, R., Upchurch, P., Goswami, A., 2014. Mesozoic mammaliaform diversity: the effect of sampling corrections on reconstructions of evolutionary dynamics. Palaeogeography, Palaeoclimatology, Palaeoecology 412, 3244

Ouaja, M., Philippe, M., Barale, G., Ferry, S., Ben Youssef, M., 2004. Mise en évidence d'une flore oxfordienne dans le Sud-Est de la Tunisie: intérêts stratigraphique et paléoécologique. Geobios 37, 8997.

Ouaja, M., Barale, G., Philippe, M., Ferry, S., 2011. Occurrence of an in situ fern

grovie the Aptian Douiret Formation, Tataouine area, South-Tunisia. Geobios 44, 473479.

Peybernes, B., Vila, J.M., Souquet, P., Charriere, A., Ben Youssef, M., Zarout, M. Calzada, S., 1996. Trois gisements de brachiopodes dans le Cretace inferieur tunisien. Batalleria 6, 4558.

Pouech, J., Mazin, J.-M., Cavin, L., Poyato-Ariza, F.J., 2015. A Berriasian actinopterygian fauna from Cherves-de-Cognac, France: biodiversity and palae-oenvironmental implications. Cretaceous Research 55, 3243.

Rambaut, A., Drummond, A.J., 2009. Tracer: MCMC Trace Analysis Tool v1.5. http:// beast.bio.ed.ac.uk/.

Rees, J., Underwood, C., 2008. Hybodont sharks of the English Bathonian andCallovian (Middle Jurassic). Palaeontology 51, 117147.

Ruban, D., 2012. Mesozoic mass extinctions and angiosperm radiation: does the molecular clock tell something new? Geologos 18 .

Ruban, D.A., 2011. Diversity dynamics of Callovian-Albian Brachiopods in the Northern Caucasus (Northern Neo-Tethys) and a Jurassic/Cretaceous Mass Extinction. Paleontological Research 15, 154167.

Saint-Hilaire, É.G., 1831. Recherches sur de grands sauriens trouvés à l'état fossile aux confins maritimes de la Basse-Normandie, attribués d'abord au crocodile puis déterminés sous les noms de Teleosaurus et Steneosaurus. Mémoire de l'Académie des Science 12, 1138.

Sauvage, H.-E., Liénard, F., 1879. Mémoire sur le genre Machimosaurus. Mémoires de la Société Géologique de France 4,1 31.

Sepkoski, J.J., 1984. A kinetic model of phanerozoic taxonomic diversity. III. PostPaleozoic families and mass extinctions. Paleobiology 10, 246267.

Syme, C.E., Salisbury, S.W., 2014. Patterns of aquatic decay and disarticulation in juvenile Indo- Pacific crocodiles (Crocodylus porosus), and implications for the taphonomic interpretation of fossil crocodyliform material. Palaeogeography, Palaeoclimatology, Palaeoecology 412, 108123.

Trucco, E., Verri, A., 1998. Introductory Techniques for 3-D Computer Vision, 201. Prentice Hall, Englewood Cliffs, pp. 178194

Upchurch, P., Barrett, P.M., 2005. Sauropodomorph diversity through time. In: Curry Rogers, K., Wilson, J. (Eds.), The Sauropods: Evolution and Paleobiology. University of California Press, Berkeley, CA, pp. 104124.

Vignaud, P., 1995. Les Thalattosuchia, crocodiles marins du Mésozoïque: Systématique, phylogénie, paléoécologie, biochronologie et implications paléogéographiques. University of Bristol, p. 350.

Wilberg, E.W., 2015. What's in an outgroup? The impact of outgroup choice on the phylogenetic position of Thalattosuchia (Crocodylomorpha) and the origin of Crocodyliformes. Systematic Biology 64 (4), 621637.

Young, M.T., 2014. Filling the 'Corallian Gap': re-description of a metriorhynchid crocodylomorph from the Oxfordian (Late Jurassic) of Headington, England. Historical Biology 8090 .

Young, M.T., Brandalise de Andrade, M., Cornée, JJ., Steel, L., Foffa, D., 2014a Re-description of a putative Early Cretaceous "teleosaurid" from France, with implications for the survival of metriorhynchids and teleosaurids 
across the Jurassic-Cretaceous Boundary. Annales de Paléontologie 100, 165174.

Young, M.T., Hua, S., Steel, L., Foffa, D., Brusatte, S.L., Thuring, S., Mateus, O., RuizOmenaca, J.I., Havlik, P., Lepage, Y., De Andrade, M.B., 2014b. Revision of the Late Jurassic teleosaurid genus Machimosaurus (Crocodylomorpha, Thalattosuchia). Royal Society Open Science 1, 140222

Young, M.T., Steel, L., Brusatte, S.L., Foffa, D., Lapage, Y., 2014c. Tooth serration morphologies in the genus Machimosaurus (Crocodylomorpha,
Thalattosuchia) from the Late Jurassic of Europe. Royal Society Open Science $1,140269$.

\section{Appendix A. Supplementary data}

Supplementary data related to this article can be found at http://dx.doi.org/10. 1016/j.cretres.2015.11.011 